\title{
Short communication: Herd-level analysis of antimicrobial use and mortality in veal calves: Do herds with low usage face higher mortality?
}

\author{
J. Bokma, ${ }^{1 *}$ (1) R. Boone, ${ }^{2}$ P. Deprez, ${ }^{1}$ () and B. Pardon ${ }^{1}$ () \\ ${ }^{1}$ Department of Large Animal Internal Medicine, Faculty of Veterinary Medicine, Ghent University, 9820 Merelbeke, Belgium \\ ${ }^{2}$ Veterinary Practice Venhei, 2460 Kasterlee, Belgium
}

\begin{abstract}
The veal calf sector fears that a too-rapid and large decrease in antimicrobial use (AMU) as demanded by European authorities would increase mortality, causing economic and welfare issues. To determine whether this concern is justified, the relationship between AMU (total and different classes) and mortality in dairy-type white veal calves, managed by 2 large veal companies, was explored. A retrospective cohort study was performed on electronically collected antimicrobial consumption and mortality data from the largest Belgian veal practice during the period 2014 to 2016. Mixed linear [mortality $(\%)$ as continuous outcome] and generalized linear mixed models with binary outcome for event and trial approach were built to identify factors associated with mortality. Data consisted of 76 production cycles from 29 farms managed by 2 veal companies ( 1 and 2 ) and covering 45,001 calves. Average AMU was $30.1 \pm 10.4$ defined daily doses for animals per year $( \pm$ standard deviation) and was higher in veal company 2 than in veal company $1(35.9 \pm 9.3$ and $22.4 \pm 5.7$ defined daily doses for animals per year, respectively). In contrast, mean mortality was lower in veal company $2(2.3 \pm$ $1.4 \%)$ than in veal company $1(4.1 \pm 1.4 \%)$. Both models showed a positive association between AMU and mortality in veal company 1 and no association in veal company 2. The final linear model identified increasing herd size and the use of third- or fourth-generation cephalosporins as risk factors for mortality and the use of long-acting macrolides as a protective factor. The final logistic model identified an increased mortality risk with increased use of third- or fourth-generation cephalosporins and sulfonamides-trimethoprim and decreased mortality when using long-acting macrolides. Based on these data, at the current levels of AMU in Belgian veal calves, an increase in mortality when reducing AMU could not be evidenced. Differences in
\end{abstract}

Received April 8, 2019.

Accepted August 25, 2019.

*Corresponding author: jade.bokma@ugent.be herd size and factors other than AMU likely better explain why one veal company faces almost double the mortality of another one. Abandoning the use of longacting macrolides might have negative consequences for mortality under the current state of the industry. The most ethical way to further reduce AMU in veal calves is likely simultaneously monitoring AMU and animal welfare parameters, starting with, but not limited to, mortality.

Key words: antimicrobial resistance, animal welfare, food-producing animal, Mycoplasma bovis, veal company

\section{Short Communication}

The veal industry, an important market for excess male calves and milk by-products from the dairy industry, is increasingly criticized for its intensive antimicrobial use (AMU), contributing to worldwide selection of antimicrobial resistance (Pardon et al., 2012a; Filippitzi et al., 2014; EMA/EFSA, 2017). The current veal production system is built on the purchase of male calves from multiple herds, which inherently exposes them to a multitude of pathogens and stressors such as transportation and commingling (Sanderson et al., 2008; Pardon et al., 2011; Hay et al., 2014; Pardon et al., 2014). Even though these large pressures make it challenging to reduce AMU, veal farms in both the Netherlands and Belgium have made massive reductions (44 and 46\%, respectively) in AMU over a short period of time. However, these reductions seem to have stabilized since 2013 and 2014, respectively (Autoriteit Diergeneesmiddelen, 2018; Bokma et al., 2019). Veal company owners, farmers, and veterinarians raised the concern that both a further reduction and the loss of critically important antimicrobials would cause an economic and welfare issue. More specifically, they fear an increase in mortality due to no longer treating animals and euthanizing earlier, as mentioned by Danish pig farmers as a consequence of the yellow card system in which measures are taken when AMU in herds exceeds a predetermined threshold (Dupont et al., 2017). Similarly, attention is brought to a potential increase in mortality when the use of critically impor- 
tant fluoroquinolones and third- and fourth-generation cephalosporins $(\mathbf{C S 3 / 4 )}$ is limited further. Meanwhile, local authorities are commissioning projects to identify potential indicators of adverse effects of a too-rapid reduction in AMU on animal welfare.

In many countries with cattle identification and registration systems, monitoring mortality would be an easily accessible way to identify undesired side effects of antimicrobial reduction (Ortiz-Pelaez et al., 2008; Bertocchi et al., 2018). Available studies show conflicting information on the relationship between AMU, disease, and mortality (Martin et al., 1980; Bähler et al., 2012; Lava et al., 2016b; Jarrige et al., 2017; Santman-Berends et al., 2018; Bokma et al., 2019). However, these epidemiological studies were not primarily designed to explore the relationship between AMU and mortality and often covered highly variable farming situations with different breeds and many different companies.

We aimed to determine whether the veal industry's fear that farms using less antimicrobials would face higher mortality is justified. Therefore, the objective of this study was to explore the relationship between AMU (total and antimicrobial class specific) and mortality risk in veal calves and whether this relationship was different between 2 veal companies. For international reference, we selected dairy-type veal calves only. The working hypothesis was that a decrease in AMU would be associated with a higher mortality risk.

A retrospective cohort study was performed. We selected appropriate data to answer the research question from an available database from the largest veal veterinary practice in Belgium, as consulted previously (Bokma et al., 2019). Sample size was determined based on the availability of data from veal farms. The source data set consisted of 342 production cycles in 83 veal farms, managed by 12 veal companies, covering 167,329 calves. Primary inclusion criteria for farms in this study were (1) fattening exclusively white veal calves, (2) at least 1 finished production cycle in the period 2014 to 2016, (3) dairy breed (mostly Holstein Friesian), and (4) belonging to the 2 largest veal companies. All calves were housed and fattened following the minimal requirements of the European legislation (EC Directives 91/629/EEC and 97/2/EC; Council of the European Union, 1991, 1997).

Antimicrobial use was expressed as treatment incidence (defined daily dose animal per year; DDDvet/yr) based on the following formula (Bokma et al., 2019):

$$
\begin{aligned}
& \text { treatment incidence }\left(\frac{\mathrm{DDDvet}}{\mathrm{yr}}\right)= \\
& \frac{\text { total antimicrobials used }(\mathrm{mg})}{\text { DDDvet }(\mathrm{mg} / \mathrm{kg}) \times \text { days at risk } \times \mathrm{BW}(\mathrm{kg})} \times 365 \mathrm{~d} .
\end{aligned}
$$

Mortality could be tracked because cattle were identified by official ear tags and death is confirmed at carcass disposal in the national cattle registration databank (Sanitrace, Animal Health Service Flanders, Belgium). Mortality risk was expressed as the number of dead calves/number of calves that arrived at the veal farm $\times 100$.

For statistical analysis, all data were transferred to SAS 9.4 (SAS Institute Inc., Cary, NC). The elementary unit was production cycle within a farm. Potential predictors considered were herd size, veal company (1 or 2), total AMU, and use of 12 antimicrobial classes: fluoroquinolones, CS3 $/ 4$, classic macrolides, longacting macrolides (MacroLA), colistin, amoxicillin, doxycycline, oxytetracycline, aminosides, florphenicol, trimethoprim-sulfonamides (TMS), lincosamides, and penicillin. Antimicrobials that were used on all farms (fluoroquinolones, doxycycline, amoxicillin, classic macrolides, and MacroLA) were tested as a continuous variable after being checked by mean-median comparison, quantile-quantile plots, histogram inspection, Kolmogorov-Smirnov test, and Shapiro-Wilk test. Wherever possible, binary variables (use or no use in the production cycle) were created and tested as well. For several antimicrobial classes (CS3/4, colistin, oxytetracycline, aminosides, florphenicol, TMS, lincosamides, and penicillin), the distribution was zero inflated and only binary variables were created.

The association of AMU (general and class specific) and mortality was analyzed in 2 ways. The first method was a maximum likelihood linear approach with mortality risk (\%) as a continuous outcome (PROC MIXED). Second, to counteract the fact that linear regression assumes that all values are possible for a mortality outcome and does not attribute a weight to every herd (larger herds have better precision around the percentage estimate), a general linear model was built (PROC GLIMMIX). The event and trial syntax was used with mortality as a binary outcome, occurring for $X n$ (number of mortality events) with a total of $X m$ trials (animals within a herd). Herd was added as a random factor to all models to account for clustering of production cycles within a herd. The model-building procedure was as follows: in the univariable analysis, predictors were withheld if $P<0.20$. Pearson and Spearman correlations were tested between significant predictors. If correlation was $>60 \%$, only the most significant $(P<0.05)$ predictor was added to the model. Next, a multivariable model was built with stepwise backward selection gradually excluding nonsignificant variables. Interactions between significant main effects were tested.

From the source data set, 76 production cycles from the 2 major veal companies met the inclusion criteria. 
These production cycles were conducted on 29 farms and covered 45,001 calves. Descriptions of the study population are provided in Table 1. Significant differences between both veal companies were identified for total AMU, oral AMU, parenteral AMU, and different antimicrobial classes (Table 1). Veal company 1 (VC1) used less antimicrobials $(22.4 \pm 5.7$ defined daily dose animal per year, standard weight; \pm standard deviation) than veal company 2 (VC2; $35.9 \pm 9.3$ defined daily dose animal per year). Mean mortality rate was $3.1 \pm 1.4 \%$ and was higher in $\mathrm{VC} 1(4.1 \pm 1.4 \%)$ than in $\mathrm{VC} 2(2.3 \pm 1.4 \%$; Table 1$)$. When plotting AMU and mortality, distinct patterns could be observed per veal company (Figure 1). A positive correlation between AMU and mortality was found for $\mathrm{VC} 1(\mathrm{r}=0.418$; $P=0.02$ ), whereas in $\mathrm{VC} 2$ no relationship was found $(\mathrm{r}=-0.08 ; P=0.58)$. In both the linear and logistic models for mortality, a significant interaction between total AMU and veal company was found $(P=0.01)$. In the logistic model, a positive association of AMU with mortality (odds ratio, $\mathbf{O R}=1.03 ; 95 \%$ CI: $1.01-1.05$ ) was seen in $\mathrm{VC1}$, whereas this was borderline not significant in $\mathrm{VC} 2(\mathrm{OR}=1.0 ; 95 \% \mathrm{CI}=0.98-1.01)$.

Risk factors univariably associated with mortality $(\%)$ in the linear model were veal company, use of TMS, and use of CS3/4. Using MacroLA was a protective factor. Veal company was not considered in the final model because it functions as a cluster variable, being strongly associated with better explanatory variables such as herd size and the use of different antimicrobial classes. The multivariable model for mortality consisted of herd size, MacroLA, and use of CS3/4 (Table 2). Larger herds showed an increased mortality risk $\left(\mathrm{R}^{2}\right.$ $=0.23 ; P<0.001$ ), farms that used CS3 $/ 4$ had higher mortality than farms that did not use any CS3/4, and a lower mortality in farms using more MacroLA was noted.

A total of 1,499 mortality events on 45,001 animals were recorded. In the univariable analysis, herd size, CS3/4, TMS, MacroLA, and amoxicillin were associated with mortality. The final multivariable logistic regression model consisted of the use of CS3/4 $(\mathrm{OR}=$ $1.2 ; 95 \% \mathrm{CI}=1.1-1.5 ; P=0.02)$, use of TMS (OR $=$ $1.2 ; 95 \% \mathrm{CI}=1.1-1.5 ; P=0.02)$, and use of MacroLA $(\mathrm{OR}=0.80 ; 95 \% \mathrm{CI}=0.65-0.98 ; P=0.03)$. In both models the herd effect was significant $(P<0.001)$. Mortality increased in farms using CS3/4 or TMS in contrast to those not using CS3/4 or TMS, whereas farms using MacroLA showed lower mortality than those not using MacroLA.

Table 1. Descriptive statistics of antimicrobial consumption and mortality data from 76 production cycles on 29 dairy veal farms, stratified by veal company, in Belgium (years 2014-2016) ${ }^{1}$

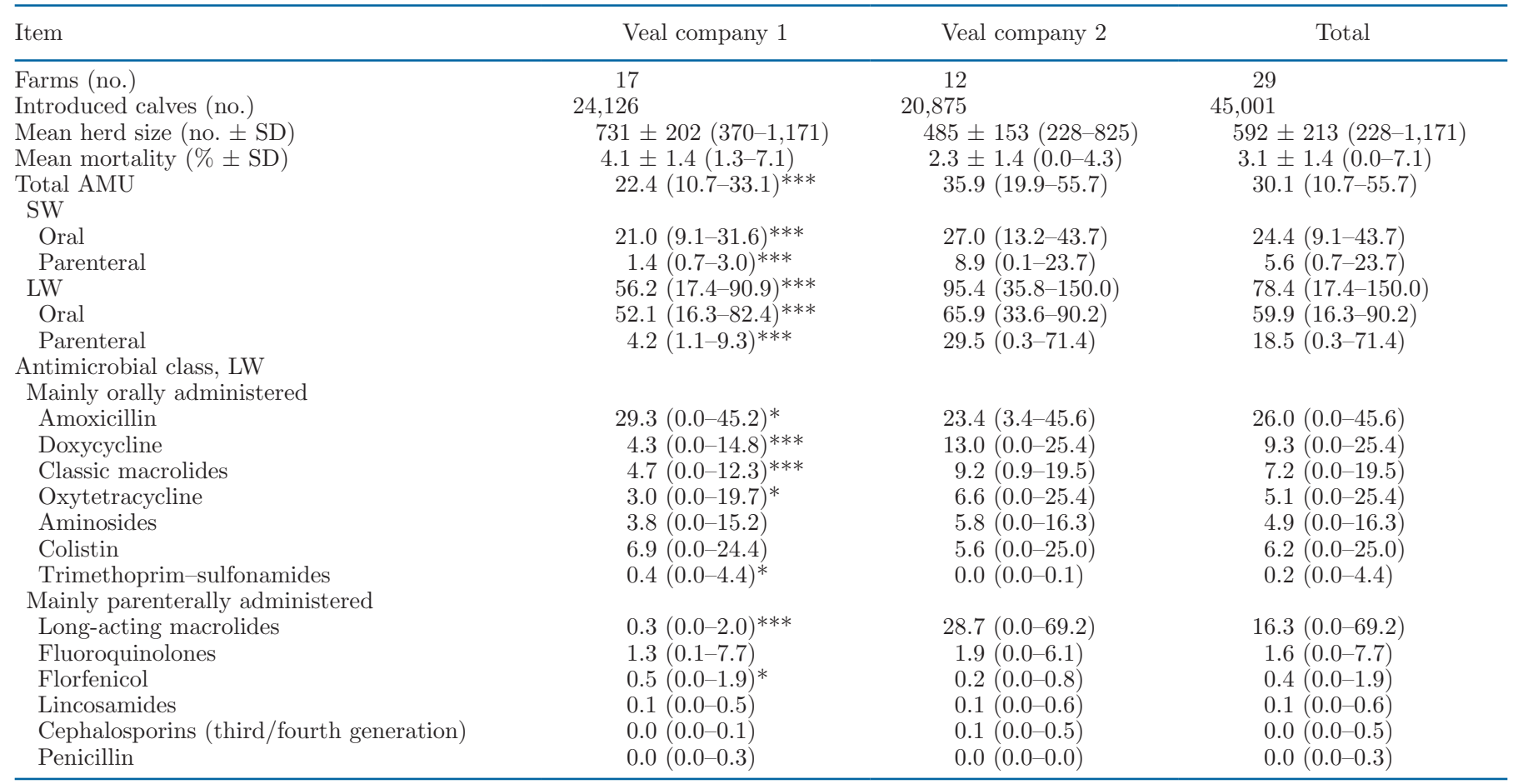

${ }^{1}$ Antimicrobial use (AMU) is expressed in veterinary daily dose per year based on standard weight (SW; $\left.160 \mathrm{~kg}\right)$ and live weight (LW). Values are presented as described or in number of production cycles (range of the interval in parentheses).

*Significantly different from veal company $2(P<0.05)$. *** Significantly different from veal company $2(P<0.001)$. 
Table 2. Multivariable linear mixed model for the association of antimicrobial use and other factors with mortality (\%) in dairy-type veal farms (76 production cycles, 29 farms, years 2014-2016, Belgium) ${ }^{1}$

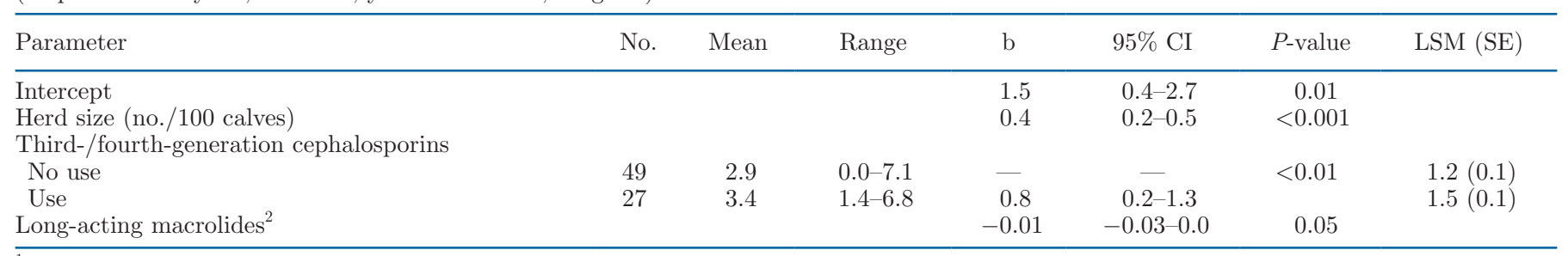

${ }^{1}$ No. $=$ number of production cycles; $\mathrm{b}=$ regression coefficient.

${ }^{2}$ For each increase with 1 defined daily dose animal per year.

Confirming or denying a negative relationship between AMU and mortality is crucial for governments and industry to be able to advance toward a further reduction in AMU. Based on this data set, we could not evidence a negative association between total AMU and mortality risk, hereby rejecting the working hypothesis. However, it should be considered that this study is prone to selection bias because a convenience sample was used and further trimmed toward only dairy-type veal calves and the largest veal companies. The veal company and veterinarian, which are frequently linked, greatly influence AMU (Gibbons et al., 2013; Postma et al., 2016). Therefore, the described associations in this study might not count for other veal calf breeds, veal companies, or veterinary practices.
An important finding in this study is the different relationship between AMU and mortality in the 2 veal companies. In $\mathrm{VC} 1$, a positive association between total AMU and mortality was seen, whereas there was no association in $\mathrm{VC} 2$. A positive association between AMU and mortality was also found in studies in Dutch and Swiss veal farms, which have similar AMU levels as VC1 (Bahler et al., 2012; Santman-Berends et al., 2018). It is possibly that in farms with this level of total AMU, antimicrobials are used in response to highly pathogenic disease, therapy failure, and mortality rather than metaphylactically. In this perspective, the positive association would represent a rational use of antimicrobials in an infectious disease situation, as prophylactic use is illegal in Belgium. The AMU of

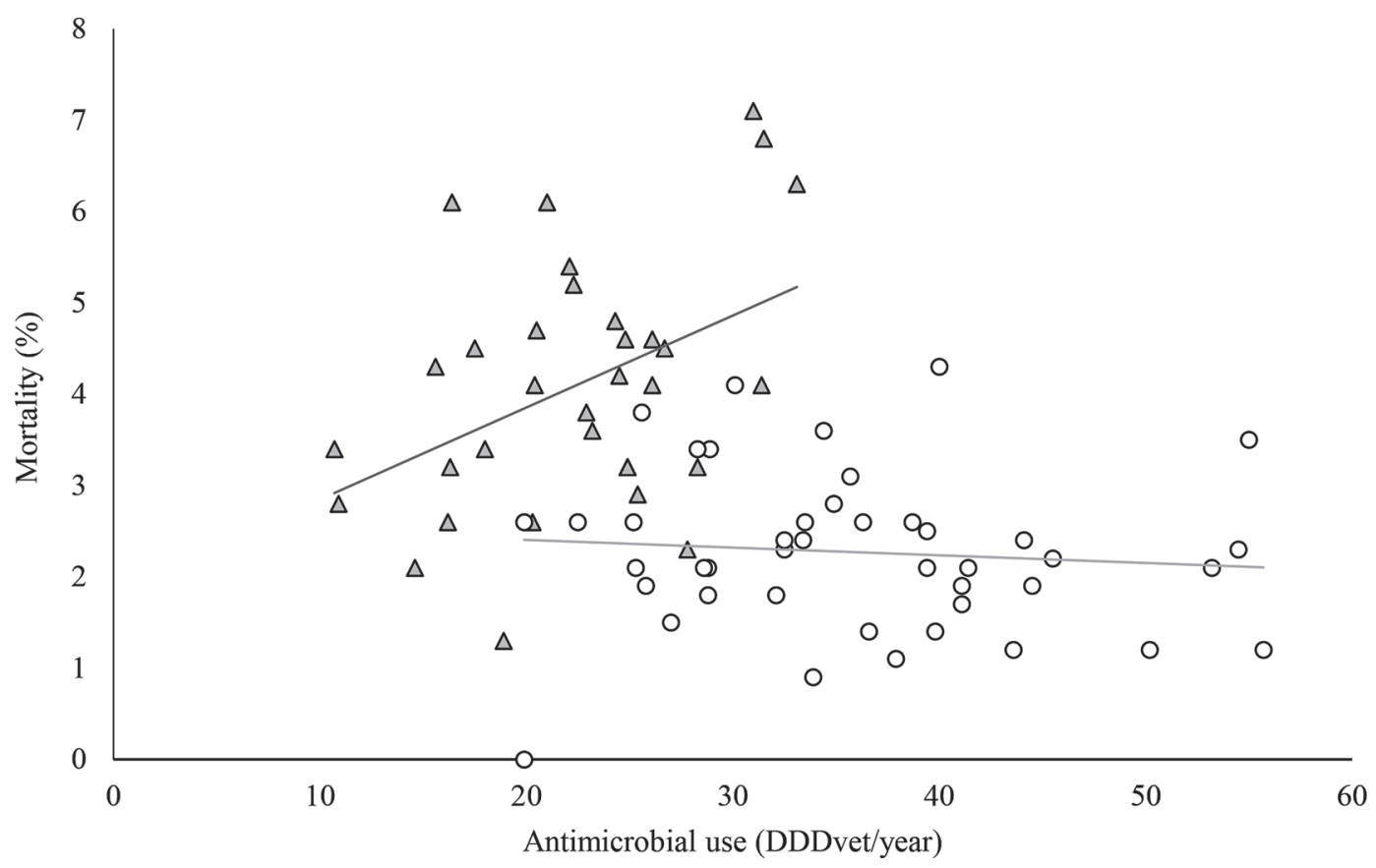

Figure 1. Association between antimicrobial use (defined daily doses for animals per year; DDDvet/year) and mortality (\%) in white dairytype veal calves (76 production cycles, 29 veal farms, years $2014-2016$, Belgium). $\mathbf{\Lambda}=$ veal company $1\left(\mathrm{R}^{2}=0.176 ; P=0.02\right) ; \bigcirc=$ veal company $2\left(\mathrm{R}^{2}=0.008 ; P=0.57\right)$. 
$\mathrm{VC} 2$ was almost double that of $\mathrm{VC} 1$, and at this level of use no relationship was seen. Potentially, excessive AMU completely blurs any relationship between use and mortality. In France, where AMU levels were even higher, only a significant association between AMU and mortality was detected between herds with high $(>5 \%)$ compared with low $(\leq 2 \%)$ mortality risk (Jarrige et al., 2017).

Even though the veal company with the lowest AMU faced approximately double the mortality of the veal company with high AMU, no significant association between AMU and mortality was observed. Other differences between both companies potentially explain this contrast better than AMU. For example, VC1 had larger herds, which is a known risk factor for mortality in veal and dairy calves (Thomsen et al., 2006; Lava et al., 2016a; Santman-Berends et al., 2018; Bokma et al., 2019). Potential reasons might be a larger degree of commingling or more difficulty observing individuals for early treatment (Bahler et al., 2012; Lava et al., 2016a). Differences in nutrition, breed, housing, purchase policy, organization of transport, and international contacts might also explain the difference in mortality much better than AMU (Pardon et al., 2012b; Winder et al., 2016; Renaud et al., 2018; Santman-Berends et al., 2018; Bokma et al., 2019).

A second concern was that lower use of critically important fluoroquinolones and CS3/4 would increase mortality. However, in both models the use of CS3/4 was associated with increased mortality. The authors reason that the use of CS3/4 would be a consequence of increased mortality rather than a cause. Given the status of CS3/4 as a reserve antibiotic in food animals, and with the veterinary practice in this study being an early participant in voluntary antimicrobial reduction, already reducing their CS3/4 use drastically, these antibiotics were likely used only in massive outbreaks of rapidly deteriorating diseases or in documented cases of antimicrobial resistance. Long-acting macrolides appeared to be a protective factor for mortality in both models. Most likely, the positive association between TMS and mortality is related to their effectiveness against Mycoplasma bovis, which is the dominant respiratory pathogen in the veal calf industry (Pardon et al., 2011). In the study population, a shift from oral group treatments to injectable MacroLA had been made in the last years (Bokma et al., 2019). The data suggest that reducing the use of MacroLA does present a potential danger of increased mortality. This is an important observation as these molecules are classified as critically important by the World Health Organization, but their use in Belgium and the Netherlands is not as restricted as CS3/4 and fluoroquinolones. This effect might be confounded by the veal company.
Third, despite the fact that mortality has been suggested as an "iceberg" indicator for animal welfare (Farm Animal Welfare Council, 2009; Richmond et al., 2017) and that both Flemish citizens and farmers consider mortality an important reflection of animal welfare (Vanhonacker et al., 2008), the authors are not confident that monitoring mortality alone would be sufficient to ensure no adverse effects of a further reduction of AMU. Today, animal welfare monitoring in daily practice is not occurring in many of the leading veal-producing countries, possibly because the available Welfare Quality assessment protocol for veal calves (Welfare Quality Network, 2006) is, although comprehensive, time consuming and complex (Grandin, 2014). As mortality registration is mostly available, monitoring mortality could be a start, as there are no reasons to doubt that welfare is hampered if many animals die within a certain production system, regardless of the reason. Whether a linear regression or a logistic (event or trail) analytic approach is used to follow trends in the relationship between mortality and AMU can be left to the discretion of the involved industry or governments because both return highly similar results. Altogether, simultaneously monitoring antimicrobial consumption data and animal welfare parameters, starting with but not limited to mortality, is likely the most ethical way toward sustainably reducing AMU and antimicrobial resistance in food animals.

\section{ACKNOWLEDGMENTS}

We acknowledge the whole team of the veterinary practice for their consistent record keeping and the farmers and integrators for participating. Data for this work were collected as part of a masters in veterinary medicine thesis in 2017, conducted at Ghent University (Merelbeke, Belgium). Jade Bokma is supported by the Belgian Federal Public Service, Health, Food Chain Safety and Environment (Brussels, Belgium; grant no. RF 17/6313, MALDIRESP).

\section{REFERENCES}

Autoriteit Diergeneesmiddelen. 2018. Usage of antibiotics in agricultural livestock in the Netherlands in 2017: Trends and benchmarking of livestock farms and veterinarians. Accessed Mar. 25, 2019 https://cdn.i-pulse.nl/autoriteitdiergeneesmiddelen/userfiles/ Publications/engels-def-rapportage-2017.pdf.

Bähler, C., A. Steiner, A. Luginbuhl, A. Ewy, H. Posthaus, D. Strabel T. Kaufmann, and G. Regula. 2012. Risk factors for death and unwanted early slaughter in Swiss veal calves kept at a specific animal welfare standard. Res. Vet. Sci. 92:162-168. https://doi .org/10.1016/j.rvsc.2010.10.009.

Bertocchi, L., F. Fusi, A. Angelucci, L. Bolzoni, S. Pongolini, R. M. Strano, J. Ginestreti, G. Riuzzi, P. Moroni, and V. Lorenzi. 2018. Characterization of hazards, welfare promoters and animal-based measures for the welfare assessment of dairy cows: Elicitation 
of expert opinion. Prev. Vet. Med. 150:8-18. https://doi.org/10 .1016/j.prevetmed.2017.11.023.

Bokma, J., R. Boone, P. Deprez, and B. Pardon. 2019. Risk factors for antimicrobial use in veal calves and the association with mortality. J. Dairy Sci. 102:607-618. https://doi.org/10.3168/jds.2018 $-15211$.

Council of the European Union. 1991. Council Directive 91/629/EEC of 19 November 1991 laying down minimum standards for the protection of calves.

Council of the European Union. 1997. Council Directive 97/2/EC of 20 January 1997 amending Directive 91/629/EEC laying down minimum standards for the protection of calves.

Dupont, N., L. H. Diness, M. Fertner, C. S. Kristensen, and H. Stege. 2017. Antimicrobial reduction measures applied in Danish pig herds following the introduction of the "yellow card" antimicrobial scheme. Prev. Vet. Med. 138:9-16. https://doi.org/10.1016/j .prevetmed.2016.12.019.

EMA/EFSA. 2017. EMA and EFSA Joint Scientific Opinion on measures to reduce the need to use antimicrobial agents in animal husbandry in the European Union, and the resulting impacts on food safety (RONAFA). Accessed Mar. 23, 2019. https://efsa .onlinelibrary.wiley.com/doi/epdf/10.2903/j.efsa.2017.4666.

Farm Animal Welfare Council. 2009. Farm animal welfare in Great Britain: Past, present and future. Accessed Mar. 23, 2019. https: //assets.publishing.service.gov.uk/government/uploads/system/ uploads/attachment_data/file/319292/Farm_Animal_Welfare_in _Great_Britain___Past_Present_and_Future.pdf.

Filippitzi, M. E., B. Callens, B. Pardon, D. Persoons, and J. Dewulf. 2014. Antimicrobial use in pigs, broilers and veal calves in Belgium. Vlaams Diergeneeskd. Tijdschr. 83:215-224.

Gibbons, J. F., F. Boland, J. F. Buckley, F. Butler, J. Egan, S. Fanning, B. K. Markey, and F. C. Leonard. 2013. Influences on antimicrobial prescribing behaviour of veterinary practitioners in cattle practice in Ireland. Vet. Rec. 172. https://doi.org/10.1136/ vr.100782.

Grandin, T. 2014. Animal welfare and society concerns finding the missing link. Meat Sci. 98:461-469. https://doi.org/10.1016/j .meatsci.2014.05.011.

Hay, K. E., T. S. Barnes, J. M. Morton, A. C. A. Clements, and T. J. Mahony. 2014. Risk factors for bovine respiratory disease in Australian feedlot cattle: Use of a causal diagram-informed approach to estimate effects of animal mixing and movements before feedlot entry. Prev. Vet. Med. 117:160-169. https://doi.org/10.1016/j .prevetmed.2014.07.001.

Jarrige, N., G. Cazeau, E. Morignat, M. Chanteperdrix, and E. Gay. 2017. Quantitative and qualitative analysis of antimicrobial usage in white veal calves in France. Prev. Vet. Med. 144:158-166. https: //doi.org/10.1016/j.prevetmed.2017.05.018.

Lava, M., B. Pardon, G. Schupbach-Regula, K. Keckeis, P. Deprez, A. Steiner, and M. Meylan. 2016a. Effect of calf purchase and other herd-level risk factors on mortality, unwanted early slaughter, and use of antimicrobial group treatments in Swiss veal calf operations. Prev. Vet. Med. 126:81-88. https://doi.org/10.1016/j.prevetmed 2016.01.020.

Lava, M., G. Schupbach-Regula, A. Steiner, and M. Meylan. 2016b. Antimicrobial drug use and risk factors associated with treatment incidence and mortality in Swiss veal calves reared under improved welfare conditions. Prev. Vet. Med. 126:121-130. https://doi.org/ 10.1016/j.prevetmed.2016.02.002.

Martin, S. W., A. H. Meek, D. G. Davis, R. G. Thomson, J. A. Johnson, A. Lopez, L. Stephens, R. A. Curtis, J. F. Prescott, S. Rosendal, M. Savan, A. J. Zubaidy, and M. R. Bolton. 1980. Factors associated with mortality in feedlot cattle: The Bruce County Beef Cattle Project. Can. J. Comp. Med. 44:1-10.
Ortiz-Pelaez, A., D. G. Pritchard, D. U. Pfeiffer, E. Jones, P. Honeyman, and J. J. Mawdsley. 2008. Calf mortality as a welfare indicator on British cattle farms. Vet. J. 176:177-181. https://doi.org/ 10.1016/j.tvjl.2007.02.006.

Pardon, B., B. Catry, R. Boone, H. Theys, K. De Bleecker, J. Dewulf, and P. Deprez. 2014. Characteristics and challenges of the modern Belgian veal industry. Vlaams Diergen. Tijds. 83:155-163.

Pardon, B., B. Catry, J. Dewulf, D. Persoons, M. Hostens, K. De Bleecker, and P. Deprez. 2012a. Prospective study on quantitative and qualitative antimicrobial and anti-inflammatory drug use in white veal calves. J. Antimicrob. Chemother. 67:1027-1038. https: //doi.org/10.1093/jac/dkr570.

Pardon, B., K. De Bleecker, J. Dewulf, J. Callens, F. Boyen, B. Catry, and P. Deprez. 2011. Prevalence of respiratory pathogens in diseased, non-vaccinated, routinely medicated veal calves. Vet. Rec. 169:278. https://doi.org/10.1136/vr.d4406.

Pardon, B., K. De Bleecker, M. Hostens, J. Callens, J. Dewulf, and P. Deprez. 2012b. Longitudinal study on morbidity and mortality in white veal calves in Belgium. BMC Vet. Res. 8:26. https://doi.org/ 10.1186/1746-6148-8-26.

Postma, M., D. C. Speksnijder, A. D. Jaarsma, T. J. Verheij, J. A. Wagenaar, and J. Dewulf. 2016. Opinions of veterinarians on antimicrobial use in farm animals in Flanders and the Netherlands. Vet. Rec. 179:68. https://doi.org/10.1136/vr.103618.

Renaud, D. L., D. F. Kelton, S. J. LeBlanc, D. B. Haley, and T. F. Duffield. 2018. Calf management risk factors on dairy farms associated with male calf mortality on veal farms. J. Dairy Sci. 101:1785-1794. https://doi.org/10.3168/jds.2017-13578.

Richmond, S. E., F. Wemelsfelder, I. Beltran de Heredia, R. Ruiz, E. Canali, and C. M. Dwyer. 2017. Evaluation of animal-based indicators to be used in a welfare assessment protocol for sheep. Front. Vet. Sci. 4:210. https://doi.org/10.3389/fvets.2017.00210.

Sanderson, M. W., D. A. Dargatz, and B. A. Wagner. 2008. Risk factors for initial respiratory disease in United States' feedlots based on producer-collected daily morbidity counts. Can. Vet. J. 49:373-378.

Santman-Berends, I. M., A. J. G. de Bont-Smolenaars, L. Roos, A. G. J. Velthuis, and G. van Schaik. 2018. Using routinely collected data to evaluate risk factors for mortality of veal calves. Prev. Vet. Med. 157:86-93. https://doi.org/10.1016/j.prevetmed.2018.05.013.

Thomsen, P. T., A. M. Kjeldsen, J. T. Sorensen, H. Houe, and A. K. Ersboll. 2006. Herd-level risk factors for the mortality of cows in Danish dairy herds. Vet. Rec. 158:622-626. https://doi.org/10 $.1136 / v r .158 .18 .622$.

Vanhonacker, F., W. Verbeke, E. Van Poucke, and F. A. M. Tuyttens. 2008. Do citizens and farmers interpret the concept of farm animal welfare differently? Livest. Sci. 116:126-136. https://doi.org/10 .1016/j.livsci.2007.09.017.

Welfare Quality Network. 2006. Collection of data for veal calves on farm (measured on farm). Accessed Nov. 21, 2018. http://www1 .clermont.inra.fr/wq/pdf/WQ_Veal\%20calves\%20on\%20farm _collection\%20of\%20data.pdf.

Winder, C. B., D. F. Kelton, and T. F. Duffield. 2016. Mortality risk factors for calves entering a multi-location white veal farm in Ontario, Canada. J. Dairy Sci. 99:10174-10181. https://doi.org/10 $.3168 /$ jds.2016-11345.

\section{ORCIDS}

J. Bokma @ https://orcid.org/0000-0002-8854-1041

P. Deprez $\odot$ https://orcid.org/0000-0003-3436-0752

B. Pardon @ https://orcid.org/0000-0003-1026-8433 